
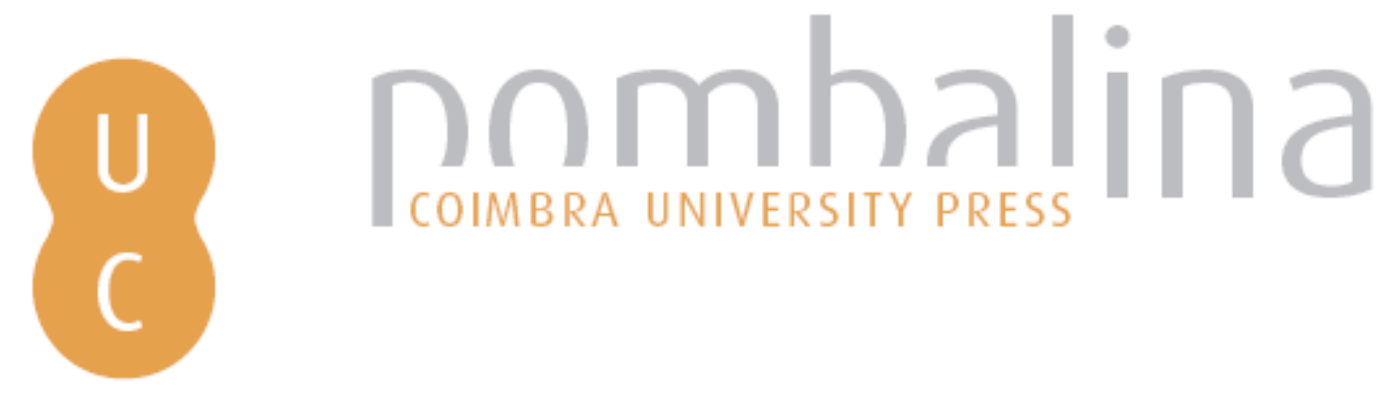

\title{
Geomorfologia e meio ambiente: uma contribuição ao estudo de áreas degradadas nos Sertões dos Inhamuns/Cratéus (Ceará, Brasil)
}

\author{
Autor(es): $\quad$ Muniz, A. C. F.; Oliveira, V. P. V. de \\ Publicado por: Imprensa da Universidade de Coimbra \\ URL \\ persistente: URI:http://hdl.handle.net/10316.2/31500 \\ DOI: $\quad$ DOI:http://dx.doi.org/10.14195/978-989-26-0534-0_49 \\ Accessed : $\quad$ 26-Apr-2023 09:17:53
}

A navegação consulta e descarregamento dos títulos inseridos nas Bibliotecas Digitais UC Digitalis, UC Pombalina e UC Impactum, pressupõem a aceitação plena e sem reservas dos Termos e Condições de Uso destas Bibliotecas Digitais, disponíveis em https://digitalis.uc.pt/pt-pt/termos.

Conforme exposto nos referidos Termos e Condições de Uso, o descarregamento de títulos de acesso restrito requer uma licença válida de autorização devendo o utilizador aceder ao(s) documento(s) a partir de um endereço de IP da instituição detentora da supramencionada licença.

Ao utilizador é apenas permitido o descarregamento para uso pessoal, pelo que o emprego do(s) título(s) descarregado(s) para outro fim, designadamente comercial, carece de autorização do respetivo autor ou editor da obra.

Na medida em que todas as obras da UC Digitalis se encontram protegidas pelo Código do Direito de Autor e Direitos Conexos e demais legislação aplicável, toda a cópia, parcial ou total, deste documento, nos casos em que é legalmente admitida, deverá conter ou fazer-se acompanhar por este aviso.

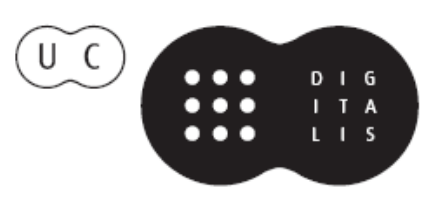





\title{
GEOMORFOLOGIA E MEIO AMBIENTE: UMA CONTRIBUIÇÃO AO ESTUDO DE ÁREAS DEGRADADAS NOS SERTÓES DOS INHAMUNS/CRATÉUS (CEARÁ, BRASIL)
}

\author{
GEOMORPHOLOGY AND THE ENVIRONMENT: \\ A CONTRIBUTION TO THE STUDY OF DEGRADED AREA IN \\ THE INHAMUNS/CRATEÚS HINTERLANDS (CEARÁ, BRAZIL)
}

A. C. F. Muniz ${ }^{1} \&$ V. P. V. de Oliveira ${ }^{2}$

Resumo - O artigo enfoca a degradação/desertificação ambiental que ocorre no Sertão dos Inhamuns, representado pelos municípios de Tauá e Arneiroz, e Sertôes de Crateús constituído pelo município de Independência, em virtude dos mesmos fazerem parte das ASDs (Áreas Suceptiveis à Desertificação) no Estado do Ceará, considerando a Geomorfologia Ambiental como área de estudo que pode auxiliar no diagnóstico da degradação das terras de regióes semi-áridas e os processos de vulnerabilidade ambiental natural existentes nessas áreas. O referencial teórico metodológico foi orientado pelo viés geossistêmico na perspectiva de BERTRAND (1969), SOTCHAVA (1976) e TRICART (1977) e de estudos geomorfológicos contemplados por HART (1986) e GUERRA (2003). Para a identificação das feiçóes geomorfológicas, utilizou-se técnicas de Geoprocessamento, através de Sistemas de Informaçóes Geográficas (SIGs), para a composição do mapeamento geomorfológico proposta por GOMES et al. (in RADAMBRASIL, 1981) na escala de 1:500.000 da folha Jaguaribe/Natal; Sistema de Coordenadas Geográficas (Datum SIRGAS 2000 - Limites municipais, IBGE-2007). Como resultados verificou-se que a ocupação humana desordenada, associada a condiçôes de semi-aridez acentuada, contribuem para que se propague, com mais intensidade, o processo da degradação/desertificação, a exemplo da área em estudo.

Palavras-chave - Geormorfologia ambiental; Semi-árido; Sertão dos Inhamuns; Sertão de Crateús; Meio ambiente

1 Doutoranda em Geografia.Universidade Federal do Ceará (UFC), Fortaleza, Ceará, Brasil; anacfmuniz@gmail.com

2 Dep. Geografia, Universidade Federal do Ceará, Fortaleza, Brasil; vladia.ufc@gmail.com.br 
Abstract - The article focuses on the environmental degradation/desertification that occur in the Hinterland of Inhamuns, represented by the municipalities of Arneiroz and Taua, and in the Hinterland of Crateus, represented by the municipality of Independence, as they belong to the ASDs (area susceptible to desertification) of the State of Ceara, considering that Environmental Geomorphology is a study area that can contribute to detect land degradation in semi-arid regions and the natural processes of environmental vulnerability that can occur in such areas. The theoretical methodological reference has been conducted by the geossystemic bias according to BERTRAND (1969), SOTCHAVA (1976) and TRICART (1977) and by geomorphologic studies developed by HART (1986) and GUERRA (2003). For the identification of geomorphologic features, GIS techniques have applied using Geographic Information Systems (GIS) applied to the composition of the geomorphologic mapping proposed by GOMES et al. (in RADAMBRASIL, 1981) on a scale of 1:500.000 of the sheet Jaguaribe/Christmas; Geographic Coordinate System (Datum SIRGAS/2000-municipal limits, IBGE, 2007). As a result, it was found that the disorganized human occupation, coupled with the sharp semi-arid conditions, contribute to intensify the spreading of the degradation/desertification processes, as the study are shows.

Keyword - Environmental geomorphology; Semi-arid; Hinterland of Inhamuns; Hinterland of Crateús; Environment

\section{1 - Introduçáo}

Os problemas relacionados à degradação ambiental começaram a ser discutidos já na década de 1970, com as Conferências de Estocolmo, realizada em 1972 e Nairóbi em 1977 no Quênia (África). Neste último evento, a desertificação mereceu especial atenção como um problema de primeira magnitude, que afeta principalmente as populaçóes que vivem nas áreas atingidas por esse processo.

De acordo com o conceito estabelecido pela Conferência das Naçôes Unidas sobre Desertificação na África em 1977, os danos causados pela desertificação tornam-se irreversíveis e desencadeiam transtornos aos sistemas ambientais e sociais, por estarem articulados com os processos econômicos, sociais e naturais, promovendo assim, em algumas regióes, o desequilíbrio da frágil relação entre clima, solo e vegetação, que se tornam mais patentes nas regióes reconhecidas como áridas e semiáridas. Tais fatores são fundamentais na diminuição da produtividade dos ecossistemas, causando diminuição no regime pluviométrico, na disponibilidade de água e nutrientes dos solos para as plantas, ocasionando deste modo a erosão nos solos, e comprometendo a evoluçáo dos processos pedogenéticos. Esses problemas são ocasionados por diversos fatores, dos quais podemos destacar: a remoção da cobertura vegetal através de desmatamento, uso de recursos tecnológicos rudimentares na produção ou transformação dos espaços naturais, queimadas, super utilização dos solos e vegetação para o desenvolvimento de atividades agrícolas, pastoris e pecuária extensiva.

A Geomorfologia tem como objetivo o estudo das formas de relevo a partir da compreensão das atuações dos processos e forças endógenas e exógenas ocorrentes no planeta Terra, as quais criam e modelam os relevos. O entendimento das diversas morfologias 
terrestres, o uso e ocupação dos solos são importantes, pois dão arcabouço informacional e metodológico para o ser humano entender as diversidades paisagísticas e propiciar o gerenciamento dos espaços geográficos de forma planejada e inteligível. Busca-se, com isso, desenvolver atividades socioeconômicas rentáveis para o desenvolvimento da sociedade humana e manutenção das dinâmicas dos sistemas naturais. Dessa forma, a Geomorfologia Ambiental emerge como um ramo da Geografia, contribuindo de forma contudente nos estudos da ecodinâmica. Em especial, destacam-se os ambientes inseridos nas regióes áridas e semiáridas, que apresentam fortes fragilidades que comprometem as atividades socioeconômicas.

Objetiva-se neste trabalho analisar a degradação ambiental nos diferentes compartimentos do relevo das respectivas áreas em estudo: Sertão dos Inhamuns, representado pelos municípios de Tauá e Arneiroz, e Sertão de Crateús, representado pelo município de Independência (Áreas Suscetíveis à Desertificação) no Estado do Ceará. A pesquisa considera os aspectos inerentes à Geomorfologia Ambiental que possam auxiliar no diagnóstico da degradação de terras das regiōes semi-áridas no balanço morfogênese versus pedogênese.

\section{2 - Revisão bibliográfica}

A Geomorfologia constitui-se num dos principais ramos da área ambiental na Geografia, pois permite identificar em campo informaçóes importantes sobre os fenômenos espaciais resultante das dinâmicas da sociedade e da natureza, tornando-se de fundamental importância para dotar o geógrafo de metodologias e contato com técnicas e instrumentos para a melhor compreensão das transformações das paisagens. Esse ramo da Geografia Física vem, atualmente, atender a uma demanda de trabalhos voltados para o Planejamento Ambiental, tanto a nível de questóes teórico-metodológicas, como de cunho prático utilitário. Assim, compreende os estudos das formas de relevo e suas transformaçóes, levando em conta a sua origem, natureza, desenvolvimento de processos e a composição dos materiais envolvidos (GUERRA, 2009).

HART (1986) citado por GUERRA (2009) fala que a origem dessa ciência não é tâo conhecida, pois o termo foi primeiramente desenvolvido por Geólogos, nos Estados Unidos, na década de 1980, sendo que os primórdios do pensamento Geomorfológico podem ser descritos por CHOLEY (1964). O referido autor atribui a W. M. DAVIS (1899) a sintetização da Geomorfologia relacionada a conteúdos reconhecidos por autores que estudavam o relevo terrestre, usando pela primeira vez o conceito de "ciclo de erosão" (GUERRA, 2009).

Dentro da ciência geomorfológica, surgiu a vertente Ambiental. Nessa perspectiva, a Geomorfologia Ambiental é uma área recente do conhecimento científico e indica o estudo das formas de relevo e processos associados a elas, que podem determinar o tipo e a taxa de mudanças estimadas pelas alteraçôes causadas na superfície terrestre pela intervenção humana. Ao procurarmos definir essa ciência e entendê-la, há que se considerar aspectos relacionados à exploração dos recursos naturais, mudanças físicas nos ecossistemas terrestres e aquáticos, quando da intervenção humana, ou de ordem natural, em virtude da ocupação desordenada do meio físico e das atividades exercidas sobre o mesmo (GUERRA, 2009). 
De acordo com GUERRA (2003), o mau uso da terra pode provocar graves danos ambientais, que se repercutem em prejuízos para o homem, até com perdas de vidas humanas. Nesse sentido, o supracitado autor diz que:

“[...] a Geomorfologia passa a ter um importante papel, juntamente com a pedologia, no diagnóstico de áreas degradadas, porque todas, ou quase todas, as atividades que os seres humanos desenvolvem na superfície terrestre, estão de alguma forma em estruturas de relevo e em algum tipo de solo [...] o conhecimento dos processos geomorfológicos podem ser de grande valia [...]" (GUERRA, 2003, p.385).

É nessa perspectiva que a ciência Geomorfológica procura compreender as formas de relevo nas diferentes escalas espaciais e temporais, sua gênese e evolução. Desse ponto de vista, a análise da degradação ambiental em seus diversos níveis, tem sido objeto de estudo dessa ciência (GUERRA, 2003). Dessa forma no campo geomorfológico, buscase entender a compartimentação topográfica regional e a caracterização e descrição das formas de relevo em cada compartimento estudado, fato este, importante nos estudos relacionados a degradação ambiental em ambientes áridos e semiáridos (SOUZA \& OLIVEIRA, 2011).

Podemos citar então que a degradação ambiental é um processo que, pela perturbação dos fluxos energéticos e ciclagens de matéria dos ecossistemas, altera total ou parcial sua configuração morfológica ou funcional. Desse modo, tais transformaçóes conduzem ao empobrecimento generalizado dos ecossistemas, fato esse que se repercute sobre a vida nele existente. Quando a degradação ocorre em áreas de climas árido, semiárido e sub-úmido seco, há uma grande tendência dessas áreas a apresentarem quadros de degradação avançada ou desertificação, a exemplo da área de pesquisa.

\section{3 - Material e método}

O Estado do Ceará ocupa uma área de $148.016 \mathrm{~km}^{2}$. Localiza-se entre as coordenadas de $3^{0} 46^{\prime} 30^{\prime \prime}$ e 7 52' 15” Lat. S e entre 37014'54” e 41024'55” Long. W. Considerando-se que a totalidade do semi-árido brasileiro situa-se no Nordeste, o estado possui cerca de 92\% de seu território inserido na Regiāo Semi-Árida, que mais oferece vulnerabilidade á incidência da desertificação. (SOUZA, 2000).

A área analisada encontra-se inserida no Sertão dos Inhamuns (Arneiroz e Tauá) e Sertão de Crateús (Independência) que, de acordo com o PAE (Programa Estadual de Combate a Desertificação no Estado do Ceará) são áreas suscetíveis a processos de desertificação no Estado do Ceará (Fig. 1). O referido documento evidencia a importância da utilização de uma análise mais completa acerca do panorama da degradação/ desertificação, através de Indicadores Geobiofísicos da Desertificação e de Indicadores Socioeconômicos, enfocando nessa perspectiva, que a desertificação emerge de uma crise ambiental em consonância com o surgimento de paisagens desérticas, se configurando em um processo de degradação nos ecossistemas semiáridos e sub-úmidos secos, que tende a desorganizar os sistemas ambientais e sociais em face de degradação ambiental (CEARÁ, 2010). 


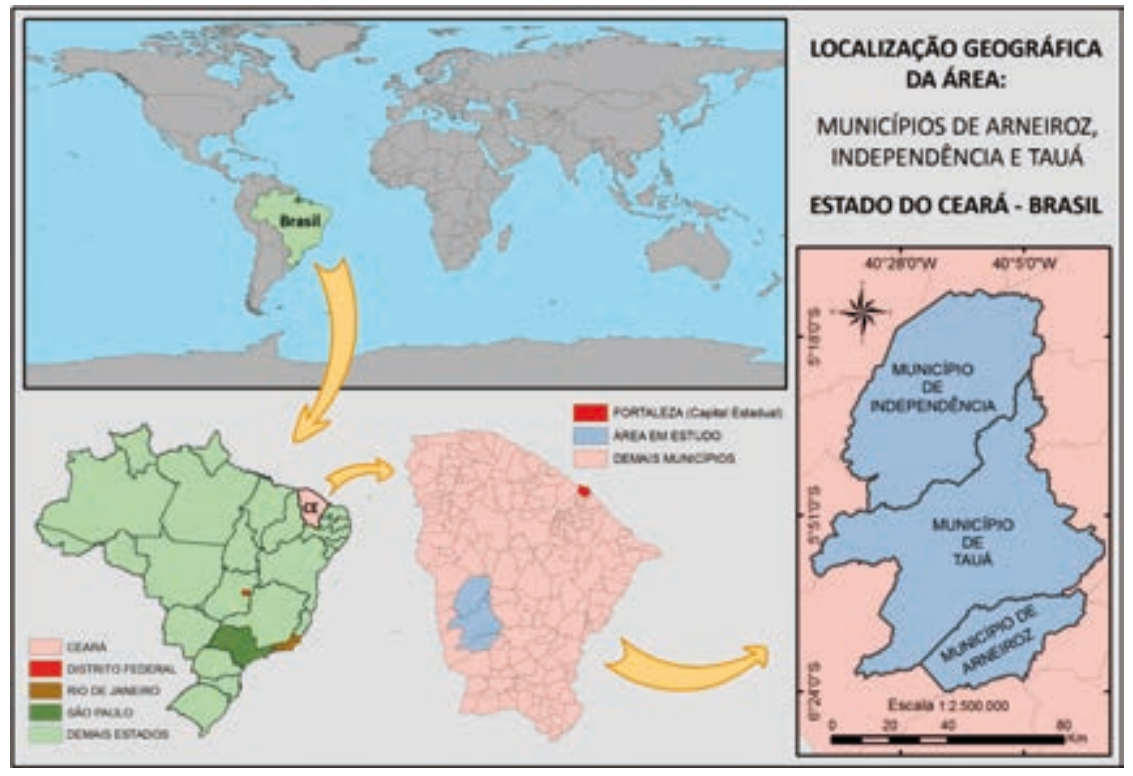

Fig. 1 - Área de Pesquisa (Municípios de Arneiroz, Independencia e Tauá - Ceará - Brasil) (IBGE, 2007, 2010).

Localizados a Sudoste do Estado do Ceará, a área de estudo abrange um total de $8.303,46 \mathrm{~km}^{2}$, com aspectos geoambientais semelhantes. O clima predominante é o Tropical Quente Semi-árido, com temperaturas médias entre $26^{\circ}$ a $28^{\circ}$ e pluviosidade média anual entre 500-700 $\mathrm{mm}$, défice no balanço hídrico, pois a quadra chuvosa se limita aos meses de fevereiro a maio. Geologicamente, quase toda sua extensão é recoberta por rochas de embasamento cristalino, com predominância de tipos litológicos como migmatitos, gnaisses e núcleos granitóides.

Com relação a compartimentação geomorfológica, quase a totalidade da área encontra-se na Depressão Sertaneja, com ocorrência de cristas e Maciços Residuais. Os tipos de modelado das paisagens dos sertóes secos são resultantes da ação conjunta dos fatores climáticos e estruturais, que também condicionam as superfícies de aplainamento escalonadas oriundas da história Plio-Quaternária regional (OLIVEIRA, 2006).

$\mathrm{Na}$ composição dos solos da área podemos destacar uma associação diversificada, mas com a predominância de Luvissolos, Planossolos, Neossolos Litólicos e afloramentos rochosos na superfície sertaneja dissecada em colinas rasas. Os solos são rasos e propícios a erosão, onde podemos observar vegetação secundária caatinga, com diferentes padróes fisionômicos e florísticos, em decorrência das condiçôes ecológicas e processos de degradação.

\section{4 - Metodologia}

Os princípios de sustentabilidade abordados para a temática da desertificação consistem em identificar e determinar indicadores que permitam a caracterização da desertificaçáo para que se possam avaliar os impactos causados pela ação antrópica em determinada área. Para tanto 
se faz necessário a adoção de um enfoque sistêmico, cujo principal objetivo foi a valorização do processo multidisciplinar. Os autores utilizados nessa etapa foram: BERTRAND (1969); SOTCHAVA (1976); TRICART (1977); HART (1986), GUERRA (2003), SOUZA \& OLIVEIRA (2002), GONÇALVES et al., (2008), MMA (2010), SOUZA \& OLIVEIRA (2011).

Sob o ponto de vista teórico-metodológico, a abordagem sistémica, que integra o conjunto das variáveis ambientais, se torna fundamental para uma análise integrada da dinâmica dos fatores geomorfológicos. Esse modelo tem-se revelado adequado para incorporar as variáveis ambientais ao processo de organização territorial e de sustentabilidade, através da consideração do ambiente como um sistema complexo, que deriva das relaçóes mútuas e interaçóes entre componentes do potencial ecológico e os componentes da exploração biológica. A análise integrada teve como base o enfoque sistêmico e considerou os fatores do potencial ecológico ligado a geomorfologia ambiental no que se sucedeu as características geoambientais local.

Para a identificação das feiçôes geomorfológicas, utilizou-se técnicas de Geoprocessamento, através de Sistemas de Informaçôes Geográficas (SIGs) para a composição do mapeamento geomorfológico proposta por GOMES et al. (in RADAMBRASIL, 1981), na escala de 1:500.000 da folha Jaguaribe/Natal. Sistema de Coordenadas Geográficas (Datum SIRGAS/2000 - Limites municipais, IBGE-2007\2010), confeccionado no ArcGIS 9.3.

\section{5 - Resultado e discussóes}

A caracterização e delimitação das unidades foram precedidas de análise sobre os componentes geofísicos considerando a influencia dos padróes de uso e ocupação do solo. Desse modo, no que se refere a superfície geomorfológica, a área se encontra em maioria na Depressão Sertaneja e Planalto Sertanejo, mas também ocorrendo áreas dos municípios nos Maciços Residuais, exibindo relevos aplainados por processos de pediplanação, ou áreas submetidas a dissecação.

A Depressão Sertaneja contempla as faixas de relevo com: Formas Aguçadas (áreas de relevo plano); Superfície Tabular Erosiva (relevo residual de topo plano); Formas Convexas (relevo de topo contínuo).

O Planalto Sertanejo se distribui em maior ocorrência a Leste do Município de Independência e Norte de Arneiroz, com Formas Aguçadas (relevo de topo contínuo).

Os Maciços Residuais ocorrem em quase todo o município de Tauá, entre limites com outros municípios. Nessa área podemos dar destaque a Serra da Joaninha onde, fica a nascente do rio Jaguaribe com altimetria variada entre $550 \mathrm{~m}$ a $850 \mathrm{~m}$ (Fig. 2).

A área mapeada detém uma superfície de aplainamento desenvolvida em rochas cristalinas, com relevos planos e moderadamente dissecados, e com eventuais níveis de serras dispersas. O papel da cobertura vegetal e dos tipos de solos são elementos fundamentais na definição das unidades geomorfológicas da área. Com relação a estes aspectos, OLIVEIRA (2011) destaca a importância do estudo biofísico para o entendimento das relaçôes sociais, econômicas e da organização do espaço, enfocando suas principais limitaçôes e problemas relacionados ao ambiente. Dessa forma, a análise da degradação ambiental nos diferentes compartimentos do relevo da área em estudo, observou as atividades desordenadas de manejo inadequado do solo nas formas de relevo predominantes no local (Tabela 1).

Os municípios de Arneiroz, Tauá e Independência têm como atividade predominante nas suas formas de relevo a agropecuária. Essa atividade proporciona perda na qualidade 
ambiental, aumenta os desequilíbrios ecológicos, afetando consideravelmente a qualidade de vida da população e do ambiente local.
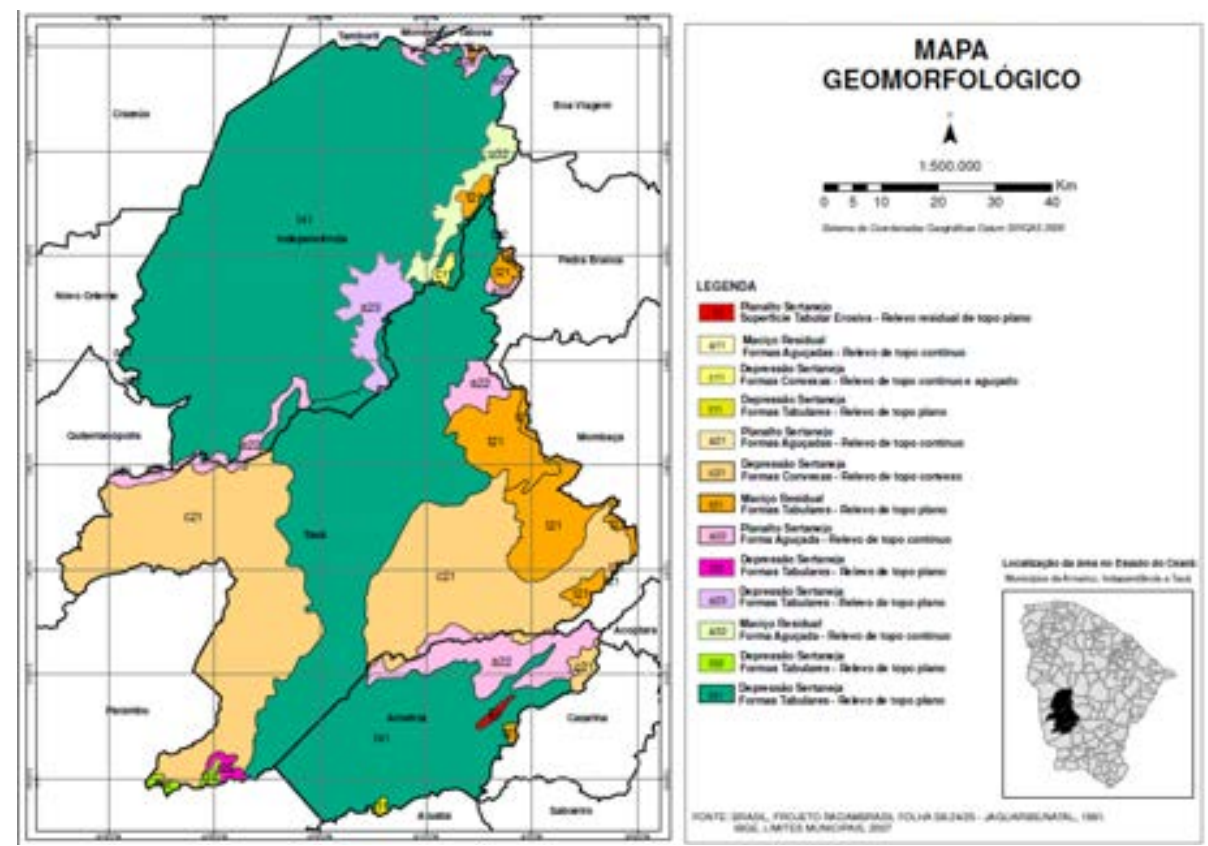

Fig. 2 - Mapa Geomorfológico da Área de Estudo (Adaptado de RADAMBRASIL, 1981).

Tabela 1 - Características Naturais Dominantes e Problemas Ambientais nas ASDs

(Inhamuns/Crateús) (Adaptado de MMA, 2010).

CARACTERÍSTICAS

NATURAIS DOMINANTES

PROBLEMAS AMBIENTAIS

\begin{tabular}{ll}
\hline $\begin{array}{l}\text { Superfície parcialmente dissecadas } \\
\text { em calhas rasas } \\
\text { e pediplanadas em rochas de }\end{array}$ & $\begin{array}{l}\text { Degradação dos solos e do recobrimento vegetal primário; } \\
\text { Superpastoreio ; } \\
\text { Complexo Cristalino }\end{array}$ \\
\hline \multirow{2}{*}{$\begin{array}{l}\text { Esconcadeamento e expansão de processos erosivos } \\
\text { acelerados, com predominância frequente de afloramentos } \\
\text { rochosos e cháo pedregoso. }\end{array}$} \\
$\begin{array}{l}\text { Perda de solo e biodiversidade empobrecida; } \\
\text { Baixa frequência de espécies lenhosas de caatinga; } \\
\text { Processos erosivos muito ativos em decorrência do } \\
\text { aumento do escoamento superficial. }\end{array}$
\end{tabular}

Dinâmica ambiental influenciada

por processos

erosivos muito ativo de

Paisagens com marcas configuradas de desertificação.

morfogênese mecânica

Historicamente, os processos de uso e ocupação das terras no Estado do Ceará resultam por consequência na degradaçáo e perda da produtividade dos solos. Isso se dá de 
maneira mais significativa no Sertão Cearense, cuja história económica mostra a predominância de atividades agropecuárias com base na criação de bovinos, caprinos e ovinos. Nas áreas favoráveis à utilização agropastoril, mas deficiente em recursos hídricos superficiais e subsuperficiais, houve uma necessidade de aumento da superfície hídrica para a ampliação de açudagem, visando a amenização dos impactos ambientais ocasionados pelas secas periódicas o que possibilitou diversificação maior das atividades rurais (SOUZA, 2000).

Nessa perspectiva, observa-se que o processo de uso e ocupação dos solos nos três municípios configurou um quadro de intensa degradação do ambiente, onde se destaca como preponderante o papel da agropecuária, seguida da agricultura de subsistência e da mineração, onde se encontram configurados os principais problemas ambientais. Desse ponto de vista, a ação antrópica na área, por meio de adoção de práticas relacionadas ao desmatamento, extração de lenha e produção de carvão, dificulta o processo de sucessão natural do ecossitesma local e aparece como um problema a conservação e preservação da área, aumentando a vulnerabilidade, em virtude da suscetibilidade ao processo de desertificação e a fragilidade ambiental do ecossistema semiárido.

\section{6 - Conclusốes}

Verificando a problemática da vulnerabilidade ambiental das ASDs no Estado do Ceará, as condiçôes naturais são determinantes para a configuração do quadro da desertificação na área em estudo, fato este que se perpetua no modelo de uso da terra que vem sendo conduzido ao longo de décadas, cuja prática se baseia na adoção de açôes conservacionistas, o que resulta na degradação generalizado do ambiente antropizado.

É notório a importância da análise sistêmica das formas de relevo para a recuperação de áreas degradadas, em virtude de várias atividades desenvolvidas pelo homem na superfície terrestre, que são influenciadas pelo manejo do solo e pelas características do meio físico.

A retirada da cobertura vegetal expôe o solo a um processo acelerado de erosão e compromete de forma irreversível (na maioria dos casos) os processos pedogenéticos. O conjunto dos indicadores biofísicos como clima, relevo e vegetação mostram a energia da erosão a que foi submetida a unidade geomorfológica, seja no passado, seja no futuro.

A ocupação humana desordenada, associada às condiçôes de semi-aridez acentuada, contribuem para que se propague com mais intensidade o processo da degradaçãoldesertificação. Os municípios em estudo se encontrarem inseridos na Depressão Sertaneja e nos Maciços Residuais, áreas com características de rangers e de extrema fragilidade face aos processos de erosão, principalmente em áreas com declive mais acentuado. Uma solução para o controle destes será a modificação e adequação dos hábitos da população na busca de práticas de manejo ambiental sustentável, com base no uso racional e na preservação futura dos recursos naturais, no sentido de controlar essa expansão através de medidas conservacionistas no uso e ocupação da terra.

\section{Referências Bibliográficas}

ArcMap $^{\mathrm{Tm}}$. ARCGIS. License type: Desktop. Version 9.3: ESRI ${ }^{\bullet}$ Inc., Copyright 1999-2008. CD-ROM

BERTRAND, G. (1969) - Paisagem e Geografia Física Global: Esboço Metodológico. Caderno de Ciências da Terra, IGEOG - USP, São Paulo, 13, p. 1-21. 
CEARÁ (2010) - MINISTÉRIO DO MEIO AMBIENTE/GOVERNO DO ESTADO DO CEARÁ/SEC. DE RECURSOS HÍDRICOS Programa Estadual de Combate à Desertificação no Estado do Ceará (PAE/ CE) - Fortaleza/Ceará.

CHOLEY, A. (1964) - Observações sobre alguns pontos de vista geográficos. Rio de Janeiro, IBGE, Boletim Geográfico, ano XXII, maio-junho.

DAVIS, W. M. (1899). The geographical cycle. Geor. Journ, London, 14, p. 481-504.

GONÇALVES, A. M., BEZERRA, C. L. \& OLIVEIRA, V. P. (2008) - Estudo Fitoecológico da Mata Ciliar Nas Sub-bacias dos Riachos Cipó e Carrapateiras do Município de Tauá - Ceará. Mercator - Revista de Geografia da UFC, 13, p. 133-147.

GUERRA, A. J. T. (2003) - A contribuição da geomorfologia aos estudos dos recursos hídricos. Bahia, Análise \& Dados. Salvador, 31, p. 385-389.

GUERRA, A. J. T (2005) - Erosão e Conservação dos Solos: conceitos, temas e aplicaçôes. Rio de Janeiro. Bertrand do Brasil, $340 \mathrm{p}$.

GUERRA, A. J. T. (2009) - Geomorfologia Ambientall Antonio José Teixeira Guerra. Monica dos Santos Marçal. Rio de Janeiro. Bertrand do Brasil, 190 p.

HART, M. G. (1986) - Geomorphology Pure and Applied. In: Allen, G. \& Unwin (Publishers), 228 p.

IBGE (2010) - Instituto Brasileiro de Geografia e Estatística - Malha Municipal 2010.

IBGE (2007) - Instituto Brasileiro de Geografia e Estatística - Malha Municipal 2007.

MMA - MINISTÉRIO DO MEIO AMBIENTE/GOVERNO DO ESTADO DO CEARÁ/SEC. DE RECURSOS HÍDRICOS (2010). Programa Estadual de Combate à Desertificação no Estado do Ceará (PAE/CE) - Fortaleza/Ceará.

OLIVEIRA, V. P. (2006) - A Problemática da Degradação dos Recursos Naturais no Domínio dos Sertôes Secos do Estado do Ceará - Brasil. SILVA, José Borzacchiello da; DANTAS, Eustógio Wanderley Correia; Zanella, Maria Elisa Zanella; MEIRELES, Antônio Jeovah de Andrade (orgs.). Litoral e Sertão, natureza e sociedade no nordeste brasileiro - José Borzacchiello da Silva et al. Fortaleza: Expressão Gráfica.

OLIVEIRA, V. P. (2011) - Indicadores Biofísicos de Desertificação, Cabo VerdelÁfrica. Mercator, Fortaleza, 10 , p. $147-168$.

OLIVEIRA, V. P., BEZERRA, C. L. \& GONÇALVES, A. M. (2008) - Estudo Fito ecológico da Mata Ciliar Nas Sub-bacias dos Riachos Cipó e Carrapateiras do Município de Tauá - Ceará. Mercator - Revista de Geografia da UFC, ano 07, 13.

RADAMBRASIL (1981) - Folhas As. 24/25 - Jaguaribe/Natal - Brasil, MME, Levantamento de Recursos. Naturais, 23.

SOUZA, M. J. N. \& OLIVEIRA, V. P. - (2011). Análise Ambiental - Uma Prática da Interdisciplinaridade no Ensino e na Pesquisa. REDE - Revista Eletrônica do Prodema, Fortaleza, 7, p. 42-59.

SOUZA, M. J. N. (2000) - Bases naturais e esboço do zoneamento geoambiental do estado do Ceará. In: LIMA, L. C., ORAIS, J. O. \& SOUZA, M. J. N. (eds.). Compartimentação territorial e gestão regional do Ceará. Parte I. Fortaleza: FUNECE.

SOUZA, M. J. N. \& OLIVEIRA, V. P. V. de. (2002) - Semiárido do Nordeste do Brasil e o fenômeno da seca in: Desastres Naturales en América Latina. Fundo de Cultura Econômica. México, p. 207-221.

SOUZA, M. J. N. \& OLIVEIRA, V. P. (2011) - Análise Ambiental - Uma Prática da Interdisciplinaridade no Ensino e na Pesquisa. REDE - Revista Eletrônica do Prodema, Fortaleza, 7, p. 42-59.

SOTCHAVA, V. B. (1976) - O Estudo dos Geossistemas. Métodos em Questão. IGEOG. USP. São Paulo 20, p. 1-19.

TRICART, J. (1977) - Ecodinâmica. FIBGE / SUPREN. 97 p. Rio de Janeiro. 